\title{
DUA ISOMER SENYAWA FLAVONOID DARI BATANG Sesbania grandiflora
}

\author{
Tjitjik Srie Tjahjandarie ${ }^{1 *)}$, Ratih Dewi Saputri ${ }^{1)}$, Nathasa Aquila Putri ${ }^{1)}$, Bella Kur- \\ niawati Dewi ${ }^{1)}$, Mulyadi Tanjung1) \\ ${ }^{1)}$ Natural Products Chemistry Research Group, Organic Chemistry Division, \\ Department of Chemistry, Faculty of Science and Technology, Universitas Airlangga, Sura- \\ baya 60115 , Indonesia
}

Korespondensi: tjitjiktjahjandarie@fst.unair.ac.id

\begin{abstract}
Two isomer flavonoids, 7,4'-dihydroxyflavanon (1) and 7,4'-dihydroxyisoflavanon (2) were isolated from the bark of Sesbania grandiflora L. Their structures were determined based on spectroscopic data such as UV, IR, MS, 1D and 2D NMR.
\end{abstract}

Keywords : Sesbania grandiflora L., flavonoid, 7,4'-dihydroxyflavanon, 7,4'-dihydroxyisoflavanon

\begin{abstract}
ABSTRAK
Dua isomer senyawa flavonoid, 7,4'-dihidroksiflavanon (1) dan 7,4'-dihidroksiisoflavanon (2) telah berhasil dipisahkan dari batang Sesbania grandiflora L. Kedua struktur senyawa isomer ditetapkan berdasarkan analisis spektroskopi UV, IR, MS, 1D dan 2D NMR.
\end{abstract}

Kata kunci : Sesbania grandiflora L., flavonoid, 7,4'-dihidroksiflavanon, 7,4'dihidroksiisoflavanon 


\section{PENDAHULUAN}

Sesbania grandiflora L. dikenal dengan daerah 'turi putih' merupakan salah satu spesies Fabaceae. Bunga tumbuhan terasa gurih dan manis digemari di Jawa dan sebagai bahan campuran pecal. Tumbuhan ini digunakan masyarakat untuk pengobatan sariawan, disentri dan luka (Heyne, 1987). Kegunaan tumbuhan turi putih sebagai tumbuhan obat tentunya sangat berkaitan dengan senyawa aktif yang terkandung dalam $S$. grandiflora $\mathrm{L}$.

Informasi fitokimia tumbuhan Sesbania sampai saat ini sangat terbatas. Senyawa flavonoid dan 2-arlbenzofuran merupakan senyawa fenolik utama yang diisolasi dari kulit batang $S$. grandiflora L. Senyawa flavonoid Sesbania mempunyai ciri khas seperti tumbuhan famili Fabaceae yakni tidak adanya gugus hidroksi di C-5. Senyawa flavonoid yang telah ditemukan pada $S$. grandiflora L. merupakan golongan isoflavan (Noviany, 2018).

Tujuan penelitian ini adalah mengisolasi dan mengidentifikasi senyawa flavonoid yang terdapat dalam batang $S$. grandiflora L. Dalam paper ini akan dilaporkan dua isomer flavonoid, 7,4'dihidroksiflavanon (1) dan 7,4'dihidroksiisoflavanon (2). Penentuan struktur kedua isomer senyawa ditentukan berdasarkan spektroskopi UV, IR, MS, 1D and 2D NMR yang menjadi fokus utama dalam paper ini.

\section{METODE PENELITIAN Prosedur umum}

Serapan panjang gelombang maksimum senyawa ditetapkan dengan spektrofotometer UV-Vis Shimadzu 1900. Gugus fungsi senyawa flavonoid diukur dengan spektrofotometer IR Perkin Elmer. Berat molekul dan rumus molekul senyawa ditetapkan dengan spektrometer massa HRESI-MS merck Waters LCT XE ESI. Spektrum NMR ditentukan dengan spektrometer NMR JEOL ECA 400 yang beroperasi pada $400 \mathrm{MHz}\left({ }^{1} \mathrm{H}-\mathrm{NMR}\right)$ dan $100 \mathrm{MHz}\left({ }^{13} \mathrm{C}-\mathrm{NMR}\right)$. Kromatografi kolom gravitasi menggunakan silika gel 60 (Merck), kromatografi radial menggunakan silika gel $60 \quad \mathrm{PF}_{254} \quad$ (Merck) dan kromatografi lapis tipis (KLT) menggunakan plat KLT silika gel $60 \mathrm{GF}_{254}$ $0.25 \mathrm{~mm}$ (Merck).

\section{Sampel penelitian}

Sampel tumbuhan yang digunakan dalam penelitian ini berupa batang $S$. grandiflora L. berasal dari Siwalan Panji, Sidoarjo dan diidentifikasi di Kebun Raya LIPI Purwodadi, Jawa Timur.

\section{Ekstraksi dan isolasi flavonoid}

Ekstraksi senyawa flavonoid yang terdapat dalam batang kering $S$. grandiflora L. (4 kg) dengan metanol sebanyak $15 \mathrm{~L}$ pada suhu ruang sebanyak dua kali masingmasingnya selama dua hari. Ekstrak metanol dipekatkan dengan alat penguap bertekanan rendah menghasilkan ekstrak kental coklat kehitaman (150 g). Ekstrak metanol dipartisi berturut-turut dengan $n$ heksana dan etil asetat sebanyak tiga kali menghasilkan ekstrak $n$-heksana dan ekstrak etil asetat (Tanjung, 2018; Tjahjandarie, 2015). Fraksinasi senyawa flavonoid dalam ekstrak etil asetat (10 g) dengan kromatografi kolom gravitasi menggunakan fasa gerak campuran $n$-heksana:etil asetat (9:1, 4:1, dan 1:1) menghasilkan lima fraksi utama A-E. Analisis KLT, fraksi D memperlihatkan pendaran ungu dengan sinar UV. Pemisahan fraksi D dengan cara yang sama menggunakan eluen $n$-heksana:etil asetat (9:1 sampai 7:3) diperoleh tiga subfraksi $\mathrm{D}_{1}-\mathrm{D}_{3}$. Pemisahan dan pemurnian subfraksi $\mathrm{D}_{2}$ dengan planar kromatografi radial menggunakan eluen $n$-heksana : diisopropileter (1:1 sampai 3:7) dan diisopropileter diperoleh senyawa $7,4^{\prime}$-dihidroksiflavanon (1) sebanyak $10 \mathrm{mg}$ dan 7,4'dihidroksiisoflavanon (2) sebanyak $7 \mathrm{mg}$.

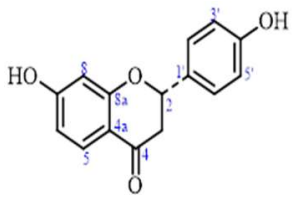

(1)

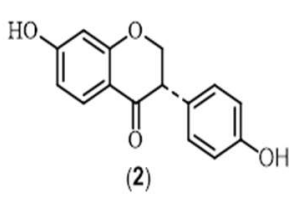

(2)
Gambar 1. Struktur 7,4'-dihidroksiflavanon (1) dan 7,4'-dihidroksiisoflavanon (2) 


\section{HASIL DAN PEMBAHASAN}

Dua isomer senyawa flavonoid, 7,4'dihidroksiflavanon (1) dan 7,4'-dihidroksiisoflavanon (2) telah berhasil dipisahkan dari ekstrak EtOAc batang $S$. grandiflora L. Penentuan struktur kedua senyawa isomer ditetapkan berdasarkan spektrum UV, IR, MS, 1D dan 2D NMR.

7,4'-Dihidroksiflavanon (1) berwujud padatan kuning dan memperlihatkan ion molekul $[\mathrm{M}+\mathrm{H}]^{+}$pada $\mathrm{m} / \mathrm{z} 257,0730$ yang sesuai dengan rumus molekul $\mathrm{C}_{15} \mathrm{H}_{12} \mathrm{O}_{4}$ berdasarkan pengukuran spektrum HRESIMS. Spektrum UV senyawa 1 dalam metanol menunjukkan serapan maksimum pada $\lambda_{\text {maks }}(\log \varepsilon): 290(4,81)$ dan $306 s h$ $(3,10)$ yang merupakan ciri khas senyawa flavanon (Marliana, 2016; 2015). Spektrum IR senyawa 1 dalam $\mathrm{KBr}$ memperlihatkan gugus fungsi hidroksi $\left(3215 \mathrm{~cm}^{-1}\right)$, karbonil terkonyugasi $\left(1715 \mathrm{~cm}^{-1}\right), \mathrm{C}=\mathrm{C}$ aromatik $\left(1546-1448 \mathrm{~cm}^{-1}\right)$ dan eter $\left(1110 \mathrm{~cm}^{-1}\right)$ (Tjahjandarie, 2015). Analisis spektrum ${ }^{1} \mathrm{H}-$ NMR (Tabel-1) senyawa 1 dalam aseton- $d_{6}$ memperlihatkan tiga buah sinyal proton doublet doublet pada pergeseran kimia $\delta_{\mathrm{H}}$ $5,44(1 \mathrm{H}, d d, J=13,0 ; 2,8 \mathrm{~Hz} ; \mathrm{H}-2), \delta_{\mathrm{H}}$ $3,04(1 \mathrm{H}, d d, J=16,8 ; 13,0 \mathrm{~Hz} ; \mathrm{H}-3$ ax $)$ dan $\delta_{\mathrm{H}} 2,66\left(1 \mathrm{H}, d d, J=16,8 ; 2,8 \mathrm{~Hz}, \mathrm{H}-3_{\mathrm{eq}}\right)$ yang khas struktur flavanon (Fatmawati, 2018). Sinyal proton aromatik sistem $A B X$ di cincin A terlihat pada $\delta_{\mathrm{H}} 7,71(\mathrm{H}-5), \delta_{\mathrm{H}}$ $6,58(\mathrm{H}-6)$ dan $\delta_{\mathrm{H}} 6,40(\mathrm{H}-8)$. Sinyal proton aromatik di cincin B terlihat pada $\delta_{\mathrm{H}} 7,39$ $\left(\mathrm{H}-2^{\prime} / 6^{\prime}\right)$ dan $\delta_{\mathrm{H}} 6,88\left(\mathrm{H}-3^{\prime} / 5^{\prime}\right)$ yang khas untuk sinyal 1,4-benzena disubstitusi (Tanjung, 2014). Analisis spektrum ${ }^{13} \mathrm{C}$ NMR (Tabel-1) senyawa 1 memperlihatkan komplet 15 sinyal atom karbon yang terpisah secara sempurna. Sinyal karbon pada $\delta_{\mathrm{C}} 80,5 ; \delta_{\mathrm{C}} 44,6$ dan $\delta_{\mathrm{C}} 190,5$ karakteristik untuk kerangka flavanon. Berdasarkan analisis spektrum ${ }^{1} \mathrm{H}$ dan ${ }^{13} \mathrm{C}$ NMR maka senyawa 1 adalah 7,4'-dihidroksiflavanon atau dikenal sebagai likuiritigenin (Varizi, 1981). Penempatan sinyal proton dan sinyal karbon yang mendukung senyawa 1 diperkuat oleh spektrum HMQC dan HMBC seperti terlihat pada Gambar 2
Tabel 1. Data spektrum NMR senyawa 7,4'dihidroksiflavanon (1) dalam aseton- $d_{6}$.

\begin{tabular}{|c|c|c|c|}
\hline $\begin{array}{l}\text { No. } \\
\text { C }\end{array}$ & $\begin{array}{c}\delta_{\mathrm{H}}(\text { mult, } J \text { dalam } \\
\mathrm{Hz})\end{array}$ & $\boldsymbol{\delta}_{\mathrm{C}}$ & НMBC \\
\hline 2 & $\begin{array}{lll}5,44 & (d d, \quad 13,0 ; \\
2,8) & & \end{array}$ & 80,5 & $\mathrm{C}-1^{\prime}, \mathrm{C}-2^{\prime} / 6^{\prime}, \mathrm{C}-4$ \\
\hline 3 & $\begin{array}{l}3,04 \quad(d d, 13,0 ; \\
16,8)_{\mathrm{ax}} \\
2,66)_{\mathrm{eq}} \\
2,8)_{\mathrm{eq}}\end{array}$ & 44,6 & C-2, C-4 \\
\hline 4 & - & 190,5 & - \\
\hline $4 a$ & - & 115,2 & - \\
\hline 5 & $7,71(d, 8,6)$ & 129,4 & C-4, C-7 \\
\hline 6 & $6,56(d d, 8,6 ; 2,3)$ & 111,1 & C-4a \\
\hline 7 & - & 165,2 & - \\
\hline 8 & $6,40(d, 2,3)$ & 103,6 & C-4a, C-7 \\
\hline $8 \mathrm{a}$ & - & 164,5 & - \\
\hline $1^{\prime}$ & - & 131,2 & - \\
\hline $2^{\prime} / 6^{\prime}$ & $7,39(d, 8,6)$ & 128,9 & $\mathrm{C}-2, \mathrm{C}-2^{\prime} / 6^{\prime}, \mathrm{C}-4^{\prime}$ \\
\hline $3^{\prime} / 5^{\prime}$ & $6,88(d, 8,6)$ & 116,1 & $\begin{array}{l}\mathrm{C}-1^{\prime}, \mathrm{C}-3^{\prime} / 5^{\prime}, \mathrm{C}- \\
4^{\prime}\end{array}$ \\
\hline $4^{\prime}$ & - & 158,5 & - \\
\hline
\end{tabular}

7,4'-Dihidroksiisoflavanon (2) memperlihatkan spektrum UV, IR dan HRESIMS sangat mirip dengan senyawa 1. Analisis spektrum ${ }^{1} \mathrm{H}-\mathrm{NMR}$ senyawa 2 (Tabel-2) dalam aseton- $d_{6}$ memperlihatkan sinyal proton aromatik sistem $\mathrm{ABX}$ di cincin A pada $\delta_{\mathrm{H}} 7,73(\mathrm{H}-5), \delta_{\mathrm{H}} 6,58(\mathrm{H}-6)$, $\delta_{\mathrm{H}} 6,39(\mathrm{H}-8)$ serta sinyal proton $1,4-$ benzena disubstitusi di cincin $\mathrm{B}$ pada $\delta_{\mathrm{H}}$ $7,12\left(\mathrm{H}-2^{\prime} / 6^{\prime}\right)$ dan $\delta_{\mathrm{H}} 6,78\left(\mathrm{H}-3^{\prime} / 5^{\prime}\right)$. Perbedaan utama sinyal proton senyawa 2 dengan senyawa 1 memperlihatkan sinyal proton metilen pada $\delta_{\mathrm{H}} 4,60(\mathrm{H}-2)$ dan sinyal proton metin pada $\delta_{\mathrm{H}} 3,84(\mathrm{H}-3)$ yang khas untuk senyawa isoflavanon (Saputri, 2018; Tjahjandarie, 2015). Analisis spektrum ${ }^{13} \mathrm{C}$ NMR senyawa 2 memperlihatkan 15 sinyal karbon yang terpisah secara sempurna. Berdasarkan analisis spektrum ${ }^{1} \mathrm{H}$ dan ${ }^{13} \mathrm{C}$ NMR maka maka senyawa 2 adalah 7,4'dihidroksiisoflavanon atau dikenal dengan nama dihidrodaidzein (Varizi, 1981). Korelasi yang penting pada spektrum HMBC yang mendukung struktur senyawa 7,4'-dihidroksiisoflavanon dapat dilihat pada Tabel-2 dan Gambar 2.

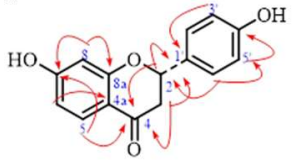

(1)

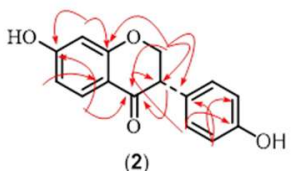

(2)
Gambar 2. Korelasi HMBC yang penting pada senyawa 1-2 


\begin{tabular}{|c|c|c|c|}
\hline $\begin{array}{l}\text { No. } \\
\text { C }\end{array}$ & $\begin{array}{l}\delta_{\mathrm{H}}(\mathrm{mult}, J \\
\text { dalam Hz) }\end{array}$ & $\boldsymbol{\delta}_{\mathrm{C}}$ & HMBC \\
\hline 2 & $4,60(d, 6,6)$ & 72,6 & $\begin{array}{l}\text { C-3, C-4, C-8a, C- } \\
1^{\prime}\end{array}$ \\
\hline 3 & $3,84(t, 6,6)$ & 51,7 & $\begin{array}{l}\text { C- } 2, \text { C- } 4, C-1^{\prime}, C- \\
2^{\prime} / 6^{\prime}\end{array}$ \\
\hline 4 & - & 191,1 & - \\
\hline $4 \mathrm{a}$ & - & 115,3 & - \\
\hline 5 & $7,73(d, 8,6)$ & 130,1 & C-4, C-7 \\
\hline 6 & $\begin{array}{l}6,56 \\
2,3)\end{array} \quad(d d, \quad 8,6$ & 111,3 & C- $4 \mathrm{a}$ \\
\hline 7 & - & 165,1 & - \\
\hline 8 & $6,39(d, 2,3)$ & 103,3 & C-4a, C-7 \\
\hline $8 \mathrm{a}$ & - & 164,4 & - \\
\hline $1^{\prime}$ & - & 127,9 & - \\
\hline $2^{\prime} / 6^{\prime}$ & $7,12(d, 8,6)$ & 130,5 & $\mathrm{C}-2, \mathrm{C}-2^{\prime} / 6^{\prime}, \mathrm{C}-4^{\prime}$ \\
\hline $3^{\prime} / 5^{\prime}$ & $6,78(d, 8,6)$ & 116,1 & $\mathrm{C}-1^{\prime}, \mathrm{C}-3^{\prime} / 5^{\prime}, \mathrm{C}-4^{\prime}$ \\
\hline $4^{\prime}$ & - & 157,5 & - \\
\hline
\end{tabular}
dan 2D NMR maka senyawa 1 dan 2 merupakan senyawa isomer. Biosintesis senyawa 2 merupakan reaksi penataan ulang, migrasi C-2 ke C-3 cincin aromatik di cincin $\mathrm{B}$ dari senyawa 1 .

\section{KESIMPULAN}

Dua isomer senyawa flavonoid yakni 7,4'-dihidroksiflavanon (1) dan 7,4' $4^{\prime}$-dihidroksiisoflavanon (2) telah berhasil diisolasi dari batang $S$. grandiflora L. Penemuan kedua senyawa tersebut mempertegas tumbuhan Sesbania memproduksi senyawa flavonoid yang tidak mempunyai gugus hidroksi di C-5 seperti flavonoid yang umum ditemukan.

\section{DAFTAR PUSTAKA}

Fatmawati, N., Anggreini, N., Saputri, R.D., Tjahjandarie, T.S., Tanjung, M. (2018). Aktivitas antimalaria senyawa flavanon terisoprenilasi dari kulit batang Phenolic compounds from the stem bark of Erythrina fusca L., J. Pharmascience. 5(1), $55-62$.

Heyne, K., (1987). Tumbuhan Berguna Indonesia, Jilid II, Badan Penelitian dan Pengembangan Kehutanan, Departemen Kesehatan RI, Jakarta.
Marliana, E., Tjahjandarie, T.S., Tanjung, M. (2016). Aktivitas antioksidan senyawa flavonoid dari Macaranga pearsonii Merr. J. Kimia Mulawarman. 13(2), 97-100.

Marliana, E., Tjahjandarie, T.S., Tanjung, M. (2015). Isoprenylated flavanone derivatives from Macaranga hosei King ex Hook F. Der Pharmacia Lettre. 7(3), 153-156.

Noviany, N., Nurhidayat, A., Hadi, S., Suhartati, T., Aziz, M., Purwitasari, N., Subasman, I. (2018). Sesbagrandiflorain $\mathrm{A}$ and $\mathrm{B}$ : isolation of two new 2-arylbenzofurans from the stem bark of Sesbania grandiflora. Nat. Prod. Res. 32(21), 2558-2564.

Saputri, R.D., Tjahjandarie, T.S., Tanjung, M. (2018). Meliglabrin, a new flavonol derivative from the leaves of Melicope glabra (Blume) T.G. Hartley. Nat. Prod. Sci., 24(3), 155-158.

Tanjung, M., Rachmadiarti, F., Saputri, R.D., Tjahjandarie, T.S. (2018). Mesucalophylloidin, a new isoprenylated 4-phenylcoumarin from Mesua calophylloides (Ridl.) Kosterm. Nat. Prod. Res., 32(9), 1062-1067.

Tanjung, M., Tjahjandarie, T.S. (2014). Isolasi dan uji aktivitas antioksidan senyawa flavonoid dari batang Bauhinia exelsa. Bionatura, 16(2), 103-105.

Tjahjandarie, T.S., Tanjung, M. (2015). Phenolic compounds from the stem bark of Erythrina orientalis and their cytotoxic and antioxidant activities. Der Pharma Chem, 7(1), 206-211.

Tjahjandarie, T.S., Tanjung, M. (2015). Lead compound antimalaria dan antioksidan senyawa alkaloid, flavonoid, dan kumarin dari Limonia accidisima L. Laporan Akhir Penelitian Unggulan 
Perguruan Tinggi, Universitas Airlangga, 1-45.

Vaziri, A., Keen, N.T., Erwin, D.C. (1981). Correlation of medicarpin production with resistance to Phytophthora megasperma f. sp. medicaginis in alfalfa seedlings. Resistance, 71(12), 1235-1238. 